\title{
Development of a "Space-Saving Model" for a One-Family Dwelling Case Study of Japanese Architecture with Space Limitations
}

\author{
Jorge Romero \\ Department of Research and Publications of Architecture, Universidad International del Ecuador, \\ Quito, Ecuador \\ Email: jromero@internacional.edu.ec
}

Received 3 December 2015; accepted 18 December 2015; published 21 December 2015

Copyright (C) 2015 by author and Scientific Research Publishing Inc.

This work is licensed under the Creative Commons Attribution International License (CC BY).

http://creativecommons.org/licenses/by/4.0/

(c) (7) Open Access

\section{Abstract}

The rapid globalization of building standards and codes in regards of contemporary housing and the growth of populations during this century demands an immediate response from designers in terms of space rationalizing to fulfill the forthcoming lack of architectural habitat on earth. The differences in culture imply a difference in the way of living, and the way of living indicates a contrast in the way of designing houses. A western house does not need an extra room covered with tatami mats for relaxation as a modern Japanese home would most likely do, as a separate living-like space. Organizations, among others, like CABO (Council of American Building Officials) and, in our specific case study, BCJ (Building Center of Japan) together with BRI (Building Research Institute) try to overcome these differences to provide better housing conditions to the world through the formulation of global designing and building standards. International publications like UBC (Uniform Building Code), IBC (International Building Code), OTFDC (One and Two Family Dwelling Code) and BSLJ (Building Standard Law of Japan) have also played an important role to globalize safety and design codes to better understand global housing under normal conditions. However, space limitations and concentration of human masses in mega cities result in a crucial new consideration: the urgent need of investigating the possibilities of rationally living within less space. Minimums provided by most codes do not take into account the space issue and overpopulation of large cities. Providing with some design recommendations for one-family dwellings has been the departure point and main motivation to carry out this case study based on actual buildings with the lack of space conditioning in a country where these conditions turn into reality.

\footnotetext{
"Corresponding author.
}

How to cite this paper: Romero, J. (2015) Development of a "Space-Saving Model" for a One-Family Dwelling Case Study of Japanese Architecture with Space Limitations. Journal of Building Construction and Planning Research, 3, $196-208$. 


\section{Keywords}

\section{Architecture, Space-Saving Design, Globalization of Building Codes, Universal Design, Minimal Architecture}

\section{Introduction}

\section{The Space-Saving Issue}

Designing space-saving homes does not necessarily mean to reduce the inner living spaces to their permissible minimums [1], but to apply several practical techniques directed to optimize and rationalize the available housing area. It is the role of our architects and interior designers, challenged by the year 2015 housing demands, to develop new concepts and techniques to offer numerous non-authoritative solutions to the small-space dilemma. We must find the answers to transform small-space houses or apartments into functional, elegant, comfortable, and highly space-efficiently personal residences [2].

Ingenious space-saving techniques such as built-in architectural components, double duty fixed or mobile furnishing, cleverly concealed beds, galleried living areas, and intelligent use of mirror are just a few answers to the complex space issue. Some of these techniques may imply subtle but often-critical architectural changes. Interior design tips such as color, pattern, and texture to visually expand small rooms do not infer architectural variations, but the results may be very effective. Every single detached house or apartment should be given personalized solutions according to its unique configuration. That is why the number of solutions is practically endless. Every home interior succeeds in a different way and should be analyzed for its design solutions, to prove that even the smallest home is far richer in possibilities than in limitations.

\section{Methodology}

Considering the need of a qualitative approach for this particular study case in Japan, a problem has been posed and a limitation has been identified: the lack of international codification in regards of architectural design within limited-space conditions. The two variables, residential architecture and geographical location, limit the study case to a geographical area, but the final recommendations, even though regarding urban domestic design, are applicable to any other country.

The final guidelines are an answer to some basic questions such as: “why regular homes underutilize space?”, "why homes do not have enough storing space?”, "why building organizations and publications do not include recommendations for space-saving architecture" and "why we do not have an international system of codes to rationalize residential space?”.

The importance of this study case remains in the fact that it provides with practical considerations to not only rationalize space that is already scarce due to urban sprawl, but to also save building costs by reducing construction area, taking into consideration both the space issue and the overpopulation problem. Moreover, these recommendations motivate other investigators to deepen into the topic and put together an international building for architects and designers, where sustainable space is its main consideration.

Two kinds of results have been achieved following this research: one through a collection of guidelines to design under limited-space conditions, and another through two different proposals of residential design. The first is an apartment pattern that could be expanded into a high-rise residential tower, and the second one is a detached house model that could be spread out as an urban residential area.

\section{Review}

\subsection{Towards the Globalization of Contemporary Housing}

Recently the idea of "International Uniform Design” has increasingly gained popularity among the people devoted to building sciences. Even though each country has its own particular housing requirements, the search for architectural universals is being done. International building codes are an example of this globalization trend [3]. The fast and effective development of communication multimedia has contributed to a better understanding of 
different cultures and consequently of different architectural needs. Each country has its own autochthonous architecture, but contemporary architecture tends to the globalization and consequently to the codification. In the design field, numerous space-saving techniques coming from different international codes or recommendations could be considered as common solutions used as an approach to a standardized international uniform design.

\subsection{Building Design Codes}

After having analyzed the Uniform Building Code and the Building Standard Law of Japan, we can realize that very few regulations are done regarding space-saving design. Most of the UBC design basics are addressed to standardize the legitimate position, effective performance and minimum distances or areas regarding various architectural components such as doors, stairways, aisles, atriums, attics, balconies, bathrooms kitchens, chimneys, columns, eaves, fences, elevators (in the case of multi-story apartment buildings), exits, garages, windows, storages, and bathrooms [4] [5].

The building codes are classified according to ten different occupancy categories. Group "R" (Residential occupancy) and its three divisions (D1: Transient residential such as hotels and motels, D2: Multiple dwellings such as apartment houses, and D3: One and two family dwellings) are devoted to regulations regarding not only the architectural components previously mentioned but also supply references on means of egress, accessibility, and interior environment, RD3 division makes provisions for the adoption of the $\mathrm{CABO}^{1}$ One and Two Family Dwelling Code. Some of the codes of the OTFDC conflict with their correspondents in the UBC by the ICBO (International Conference of Building Officials) [5].

The antagonism between different codes and the scarce number of references regarding housing design should be an incentive to promote research on International Uniform Housing Design Standardization. The Building Standard Law of Japan — established in 1950 — supply mainly with broad but fundamental provisions regarding building requirements in general. The Enforcement Order, instead, deals with more specific details, but still not abundant enough in the design field to be considered satisfactory. The BSLJ is applicable to all buildings and integrates building codes on safety aspects mostly —as it is perfectly understandable due to the particular characteristics of Japan-dealing with the risk of earthquakes and fires or conflagrations because of the densely populated urban areas [5]. Research on building design codes and more specifically on housing design codes is necessary to ensure not only the safety aspects of housing, but also a high performance and quality of living space. In highly dense population areas like many cities in Japan, Europe, North and South America further recommendations are necessary to increase the space productivity by saving and rationalizing it.

\subsection{Space-Saving Examples}

\subsubsection{Capsule Hotels}

Even though the name "capsule hotel" may suggest a "capsule apartment", it is only the result of a bedroomspace reduction. In dense urban areas, the sleeping capsule-area is neither wider nor longer than a single bed, and the customer just has the necessary space to sit upright. One capsule usually has a $2 \times 1 \times 0.8$-meter space. A capsule is not an empty box since it is usually equipped with a TV set, reading light, radio, alarm clock and even a smoke detector. These hotels - which can often be found near the main stations - are often well equipped with bar, relaxing room and even sometimes with a sentoo (Japanese bath).

All these extra facilities are connected to the bedroom capsules through the entrance lobby and corridors between capsules. Capsule hotels were created in 1975 mainly to provide a practical answer to the problem of increasing property costs and distances between the family homes and their workplace. For a small quantity of money, a worker who lost his last train home may count with a safe and comfortable space to spend the night over.

\subsubsection{Capsule Apartments}

"Capsule apartments" use the same basis concept of "capsule hotels" regarding space-reducing design, but provide the customer with all the necessary spaces not only for sleeping but also for eating, living and cooking. Sanitary services are included within the apartments, while the "capsule hotels" only have detached toilets.

"Capsule apartments" are usually prefabricated modules that are attached to a strong structural frame. Good examples of this type of apartments are those designed by Kisho Kurokawa for the Nagakin Capsule Tower in

${ }^{1}$ Council of American Building Officials, One and Two Family Dwelling Code, Washington DC. 
central Tokyo. In this building, the organization of individual space takes a new perspective since the studios are private individual capsules attached to a vertical service column. The capsule tower is a project that favors the use of individual space and individualism itself. One individual cell reflects the minimum living space equipped with TV set and audio system, incorporated air-conditioning system and compact-bed area, integrated telephone and compact bathroom. These capsules present the great advantage of being a compact prefabricated model so that they can be replaced anytime by newer versions in a short period of two weeks.

\subsubsection{Non-Prefabricated Space-Saving Designed Houses}

A good example of space-saving design architecture is the Tadao Ando's Sumiyoshi House (1975-76 Osaka). It cannot be categorized as a compact module, because it is not prefabricated and its rooms, even though small, respect the minimum standard living areas. The house is not a prefabricated capsule attached-together with others - to a main structural frame; on the other hand, it is constructed on site using reinforced concrete as the mail building system.

The basic concept of these types of houses is a fusion of the aesthetic simplicity and functional space-saving. Toyo Ito has also experimented with space-saving design. His small "House for Craftsmen" meets the architectural equivalent of simplicity. The house integrates living and working spaces. The steel structure is covered by rough industrial material such as folded steel sheets for sunshields, aluminum frames and glazed sliding doors.

\subsubsection{Prefabricated Space-Saving Designed Houses}

Like capsule apartments, prefabricated space-saving houses can be transported in one peace and attached to the main structure. Capsule apartment area is reduced to a non-standard minimum while prefabricated space-saving models, even though small, give the users a standard habitable area for a good-quality housing-space performance. A good example of this type of housing are the multi-story modular blocks developed in Hakney (England) to outcome with an innovative and more efficient building method for compact models as to reduce construction costs and skills. The steel modules are completed with fixtures and fittings, including carpets, kitchens, bathroom, and electrics.

\subsubsection{Micro Architecture and Minimal Architecture Fusion}

Micro architecture has to do with space-reduction techniques to its conceivable minimums. The particular shapes than can be grouped under this context are the "capsules", tiny huts and other type of experimental reduced-area dwellings. The well-known lack of public space characteristic of many Japanese cities has largely contributed to the development of the so-called "micro architecture". The predominance of unagi-no-nedoko (short frontage land lots) has also contributed to develop an architecture with minimal consequences like "Aura house" in central Tokyo on a $3.5 \times 20$ meter site. The house made with concrete walls and translucent fabric is lying between taller commercial buildings in Ginza area.

On the other hand, minimal architecture does not mean small houses as its name may suggest. Minimalism is a concept widely used to describe the kind of architecture with a minimum amount of means; therefore, eliminating anything superfluous and useless space. Minimalism is characterized by lack of decorative and ornamental expression. An apartment designed by $\mathrm{M}$. Guard in London explores the maximization of reduced available space through flexibility. The lack of interior fixed walls provides a large space for living or working. This area can eventually be divided in sub areas through flexible wall-doors. Another project by Fairbanks Architects in New York City shaped a loft with minimalism characteristics. The project is distributed inside a volume with a mezzanine. The ground floor contains the living, dining and one bedroom. The mezzanine contains the second bedroom. The opaque-glass sliding doors on the front of the two bedrooms divide the private from the non-private areas. Here, again, simplicity and flexibility of spaces are the project common denominator.

A reasonable balance between these two contemporary architectural trends produces architecture capable of satisfying the user's space needs in a rational and saving way. The result of this fusion fulfills not only the living and psychological requirements of the dwellers, but also allows them to reduce increasing and excessive building and material costs as well as construction time.

\section{Discussion}

\subsection{Housing Standards}

The Ministry of Construction has established the housing standards as five-year plans in order to provide people 
with secured and comfortable housing life. In this five-year plan, different kinds of standards have been set up such as the Minimum Housing Standards (standards that every household should attain), the Average Housing Standards and the Targeted Housing Standards (standards that half of the households should attain by year 2020). Among the Targeted Housing Standards the following two categories have been set up: the Standards for Urban Dwellings and the Standards for Ordinary Dwellings [6].

Each category of the standards deals with the following criteria regarding space.

1) Dwelling rooms: bedrooms, dining rooms, living rooms, etc.

2) Facilities: toilets, bathrooms, etc.

3) Dwelling environment.

4) Size of dwellings by number of household members: number and kind of rooms, area of dwelling rooms, net floor area, etc. [7].

\subsection{Global Housing}

Recently the idea of "Global housing” has increasingly gained popularity among the people devoted to building sciences. Even though each country has its own particular housing requirements, the search for architectural universals is being done. International building codes are an example of this globalization trend. The fast and effective development of communication multimedia has contributed to a better understanding of different cultures and consequently of different architectural needs, such as the case of imported wooden houses from Canada [8] [9]. Each country has its own autochthonous architecture, but contemporary architecture tends to the globalization and consequently to the codification. In the design field, numerous space-saving techniques coming from different international codes or recommendations could be considered as common solutions used as an approach to a standardized international uniform design. The Australian case has also been regarded as an alternative to imported houses from Canada as long as they be reinterpreted with the specific requirements of Japanese detached houses [10].

\subsection{Universal Design and Housing}

\subsubsection{General Guidelines}

All members of the household should benefit from safer homes that impose fewer constraints on daily activities. Accessible and universal designed housing allows families to live together in preferred places instead of facing the emotional and economic costs of moving or institutionalizing a family member. Universal design in housing allows for the housing for the lifespan of all people; households can "age in place" over the life cycle without incurring significant remodeling expenses. Universal design features in housing refers to characteristics which benefit everyone.

\subsubsection{Fair Housing}

Fair housing refers to practices that comply with the federal Fair Housing Act, carried out by the US Housing and Urban Development, originally passed in 1968, and similar state and local laws. The Fair Housing Amendments Act of 1998 is intended to strengthen enforcement of Fair Housing requirements by extending to persons with disabilities and to families with children the same kinds of nondiscrimination protections afforded to persons based on race, color, religion, sex, and national origin [4]. Thus, the Fair Housing Act protects persons with disabilities from discrimination in any activities relating to the sale or rental of dwellings, in the provision of services or facilities in connection with such dwellings, and in the availability of residential real estate related transactions.

\subsubsection{Housing Modifications}

Some people are born with a disability. Moreover, throughout life, all people experience changes in their abilities. With foresight and action, they can forestall or prevent some kinds of changes, and remedy others. However, certain changes, such as alterations in eyesight around middle age, are nearly universal, and others, such as accidental injury to a leg, cannot be foreseen. Changes may occur at any age and may be temporary or permanent. Some may be more severe than others. They may take place gradually because of aging or suddenly because of trauma. There may be a reduction in hearing, a loss of vision, or a decline in sense of smell. Sense of touch and dexterity (skill with the hands and the fingers) may diminish, or strength and flexibility in the arms and the legs 
may lessen. Mobility and agility may become limited. Balance and coordination may present challenges. Even cognition, "the act or process of knowing including both awareness and judgment" may be affected.

Often, problems occur in combination. For example, both diminished hearing and low vision are not unusual in an elderly person. Further, when one ability diminishes, it may affect another, especially a closely related one. For example, loss of sense of touch may affect dexterity. Such problems can have significant implications for carrying out routine activities around the home. The problems and their implications need not prevent people from enjoying life and independent living for many more years, however. Basic home modifications and well-designed products can facilitate independent living and privacy. They can save time, promote ease of use, and offer convenience. They can add to a home's safety too.

\subsubsection{Universal Design}

Universal design is the design of products and environments to be usable by all people, to the greatest extent possible, without the need for adaptation or specialized design. The intent of universal design is to simplify life for everyone by making products, communications, and the built environment more usable by as many people as possible at little or no extra cost. Universal design benefits people of all ages and abilities.

\subsubsection{Universal Safety Design}

A new interpretation of universal design deals not only with globalization of international building codes for aged or handicapped people, but also with international safety regulations such as the choice of the right noncombustible materials, cheaper retardant materials, stronger structural wooden and log construction as it is the case in Japan. All these safety regulations still need to be studied, standardized and ultimately globalized [11][14].

\section{Space-Saving Recommendations}

\subsection{Storage Areas}

Increasing the closet usable storage space in at least 50 percent more could do this. Closets are usually included in the house-due to cost reasons - as a simple open storage place. The closet system should provide versatility and efficient organization as to accommodate a variety of adjustable shelving and drawers. The hanging space is usually should fit the user's specific needs. Each element to be stored should have its own required space so that closet, once filled, accommodates its previous capacity and an additional usable space that may vary from the 30 percent to 70 percent more. In western styled houses, the tendency is to fulfill the closets with lots of shelves and drawers. In Japan, closets are often left free of shelving to accommodate futons and blankets. Shelves adapted to these needs should be done to take profit of the upper remaining space. Closets in Japanese houses, even smaller, are more numerous than in western styled houses and tend to be as near as possible to the places where they are needed. Western houses tendentiously contain bigger closets but less numerous. Among the advisable closet elements to increment space productivity are sock, shirt and pant dividers, shoe racks or slant shoe cases, clothing wire baskets, drawer dividers, coat, hat, tie, and belt hooks, and multipurpose drawers.

\subsection{Living Areas}

A common tendency in eastern and western styled houses is to incorporate the living area with the kitchen, so that a 30 percent of a detached living room space is saved. Japanese houses usually include a tatami room as an extra living space. In this case, the living room could be detached from the kitchen but attached to the tatami room. The four-and-a-half mat pattern should be the minimum advisable tatami room. The living areas may be joined together in order to improve their space efficiency. Dining rooms are usually conjoined with living rooms, and sometimes the kitchen itself could be comprised in the dining room.

\subsection{Entrance Halls and Corridors}

Even though passageways that open onto the different rooms are necessary within the house, entrance halls and corridors should be minimized as much as possible. For detached houses, this is easier to be done due to the quadrangular conformation. Apartments in multi-story buildings are usually rectangular; this elongated shape produces a distribution of architectural spaces along an axis; consequently, corridors tend to be longer to give ac- 
cessibility to the different rooms. In western houses, the entrance hall, preceding the distributional corridor, usually constitutes by itself a small room, from which the main corridor and stairs to the second floor are accessed. Japanese entrance hall is usually an integrative part of the main leading corridor, where an incorporated additional area is necessary for the shoes and the shoe case. A change in floor level is inevitable. Adding an extra function to the entrance corridor maximizes corridor space productivity and minimizes its circulation function.

\subsection{Kitchens}

The work triangle walking distance should be the shortest possible; that is, the three main kitchen's components should be near. In U-shaped and L-shaped kitchens the distances between the primary cooking surfaces, the sink and the refrigerator form a triangle. The most favorable distance between the three elements is the straight line. In fact, I-shaped kitchens are the best answer to space problems. When the space problem is critical no elements should interfere this linear sequence. Wall and base cabinets should include specialty storage aids such as multi-purpose drawers, vertical dividers according to the objects stored, silverware racks to avoid panel divisions, slide-out shelves, and rotatory angle shelves, where possible. Cabinets over the refrigerator are also very useful. Walkways should not interfere with the kitchen's countertop frontage and the eating area. The countertop frontage should be wider enough to work at and is usually included in the eating area to save space, but anyway, no less than its minimum clearance. The kitchen storage space could be improved by the use of a built-in stove and cabinets over the ventilation hood. These few recommendations adapt well to one of the kitchen design basics stating that a kitchen works better when a person does not have move too much from the main cooking surface.

\subsection{Bathrooms}

Limitations on space availability usually lead houses to have just one bathroom. To increase bathroom efficiency, it is necessary to separate its components so that three or at least two people can use it at the same time. Toilet, sink and bathtub areas could be reduced laterally up to an acceptable limit, but we have to have in mind the required front clearances. Clearance recommendations for the toilet frontage, tub and shower front effective area, and the distance between the toilet or lavatory center to any obstruction on either side vary from country to country. However, we can consider the need of front and lateral clearance a universal in building design. Japanese houses usually adopt the three-piece bathroom, while the western houses integrate the components in one space. The built-in bidet eliminates the need of an extra space inside the bathroom. Enough counter and shelf space around the lavatory, toilet and tub should be provided for storage, toiletries and towels.

\section{Conclusions}

Much more detailed research is needed regarding the space-saving issue to produce a more consistent set of general and specific recommendations. The above criteria are just a few design basics we should have in mind to optimize the space use. Some recommendations imply subtle but effective changes in design like the direction of the swinging-door opening or the sliding-door choice so that the opening-angle area is free. Some other proposals, instead, may involve more substantial alterations to the interior living areas like the reduction of wall section or the inclusion of a storage area. And finally, other references do not infer any physical change to the living areas, but the results may be as effective as though they did. These suggestions imply a change in the user's psychological perception. For example, we can make a bathroom look bigger with smart use of mirrors, colors and lines.

In a society with an increasing population, saving space should be taken more seriously into consideration to be able to produce an appropriate design system that does not conflict with general design building codes. In some circumstances, space limitations are a serious problem that makes it impossible, for the family members, to move comfortably between home spaces. Also, narrow corridors and stepladders may become risky not only for the elderly, but also for children and adolescents. Housing standards and global hosing should take into account the space issue as a result of overpopulation to identify new design solutions that provide a better way of using and rationalizing small spaces conditions to ultimately improve the human habitat under these circumstances. Housing modifications give a fresh and value-added design to homes which have been conceived without proper space-saving recommendations. Finally the fusion between universal design and space-saving solu- 
tions would end up with a set of new consideration for homes owned by elderly and disable people. The impact of rationalizing and saving space on human masses at a global scale would definitely help preserve our environmental and space-living conditions.

\section{Space-Saving Models}

The following illustrations are an example of two projects suggested for graphically understanding the possibilities of space-saving architectural design: one for an apartment with space limitations with possibility of expanding in height as a multi-story apartment building (Illustrations 1-4), and another for a two-floor single home with potentiality of developing horizontally as a modern urbanization of detached houses (Illustrations 5-10).

\subsection{Proposed Space-Saving Model for an Apartment}

Please place Illustrations 1-4 here with their corresponding descriptions accordingly, to acceptable design and layout: size and style (probably a one-column or two-column layout). Feel free to place and resize the images as needed.

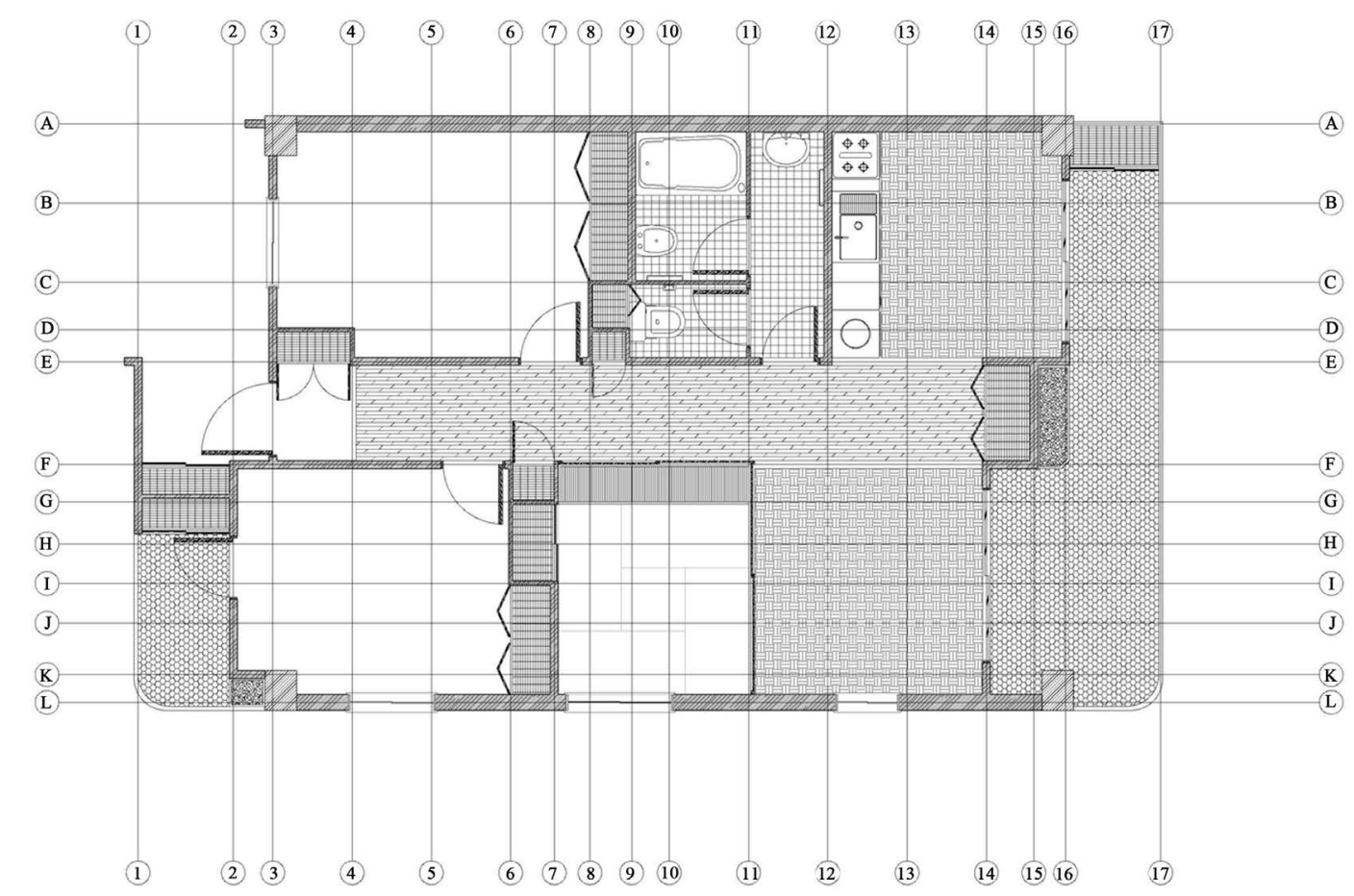

Illustration 1. First apartment model developed in accordance with the recommendations described above.

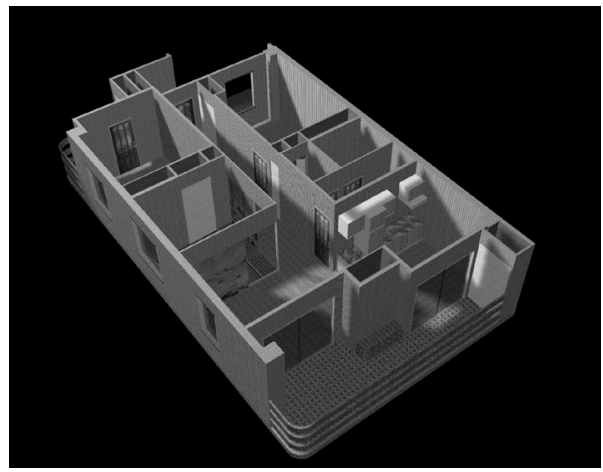

Illustration 2. Three-dimensional rendering of the same model. 


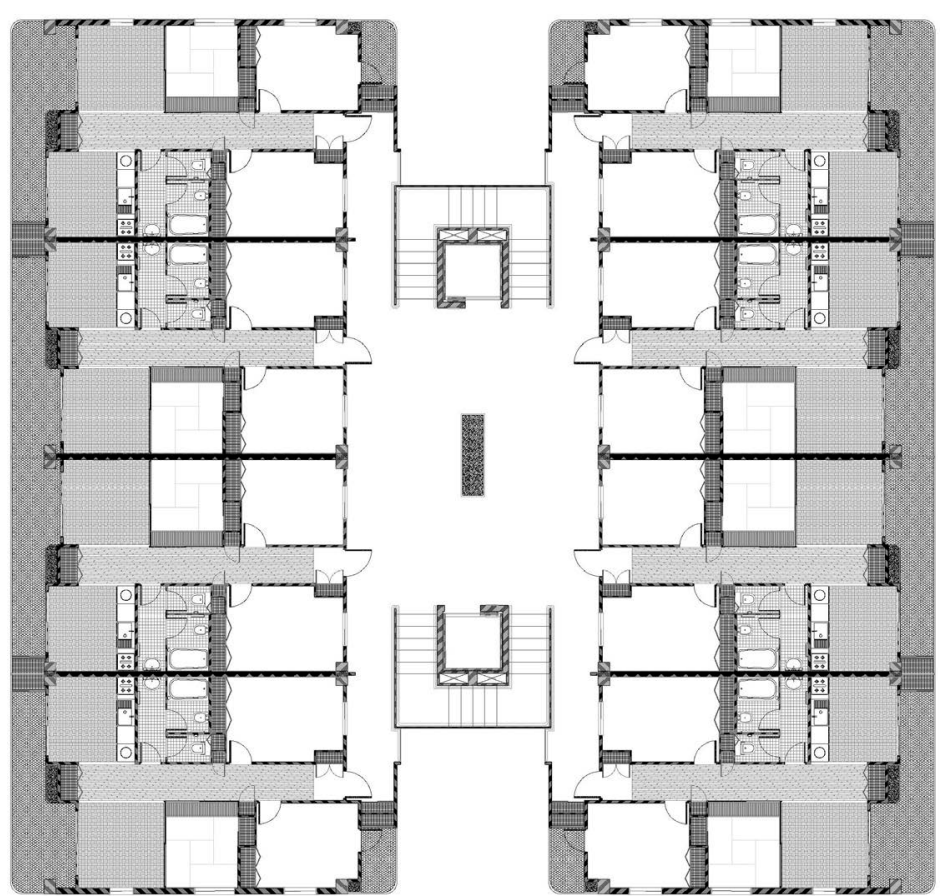

Illustration 3. The possibilities of expanding the models are endless. It is the role of us architects and interior designers, challenged by the year 2015 housing demands, to develop new concepts and techniques to offer numerous non-authoritative solutions to the small-space dilemma.

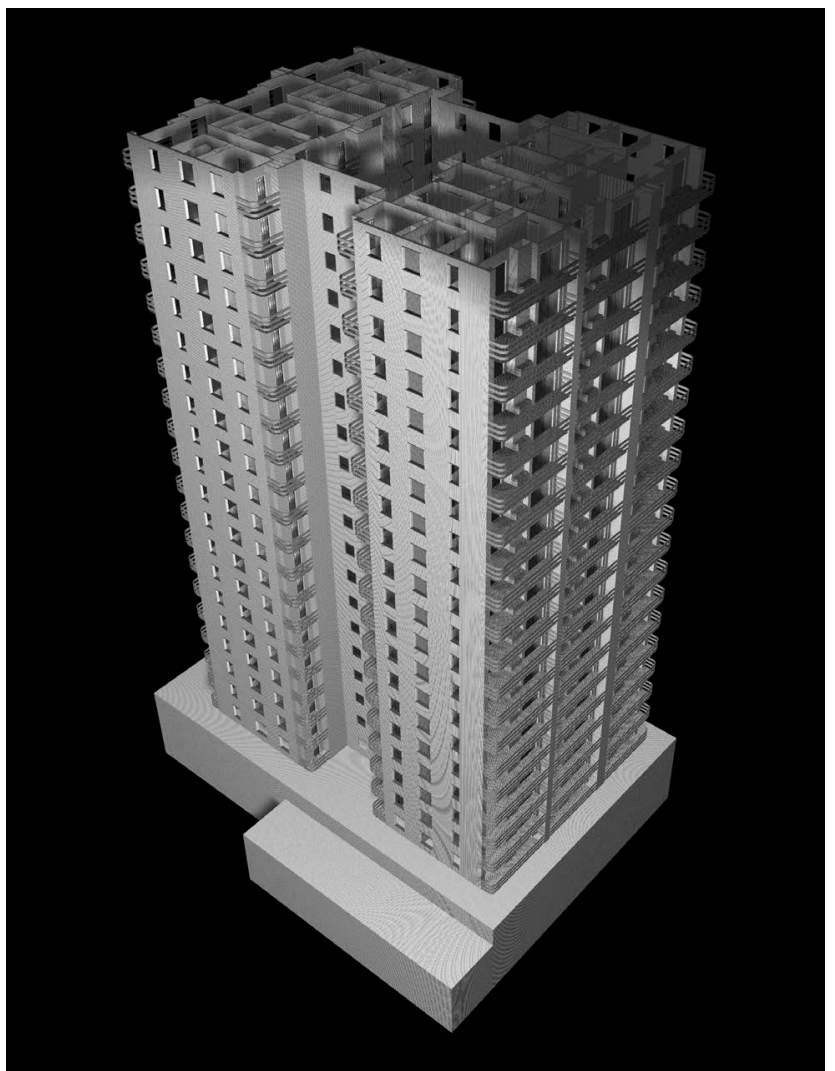

Illustration 4. Expansion of the space-saving model vertically. 


\subsection{Proposed Space-Saving Model for a Detached House}

Please place Illustrations 5-10 here with their corresponding descriptions accordingly, to acceptable design and layout: size and style (probably a one-column or two-column layout). Feel free to place and resize the images as needed.

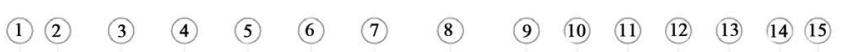

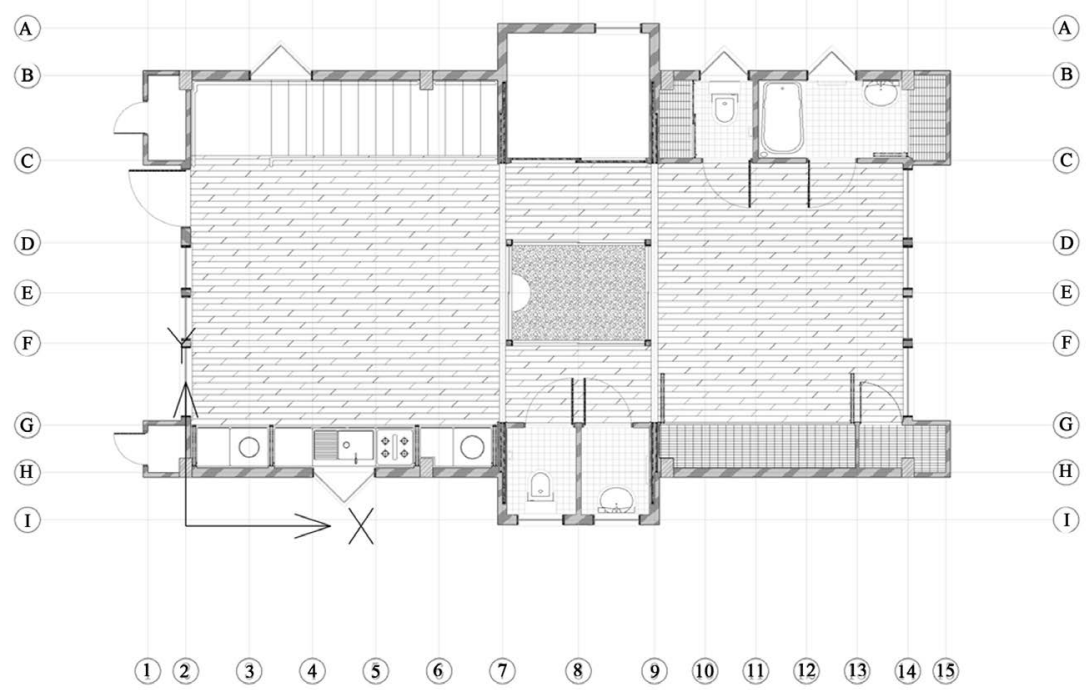

Illustration 5. Development of the second model: a detached two-story house. First floor. This model tends to be more international but still keeping some principles of uniform design and some components of Japanese architecture.
(0) (1) (2)
(3) (4)
(5)
(6) 7
(8)
(9) (10) (11) (12)
(13) (14) 15 (16

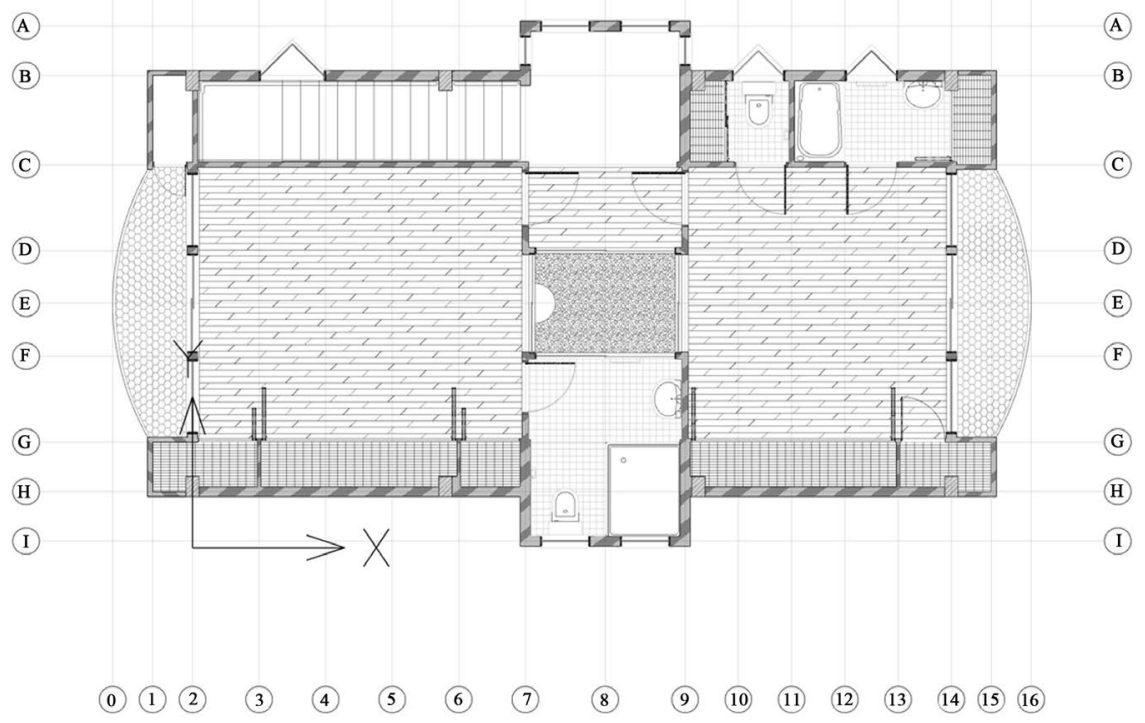

Illustration 6. Development of the second model: a detached two-story house. Second floor. The simplicity (minimalism) of Japanese architecture makes of limited spaces a functional solution. 


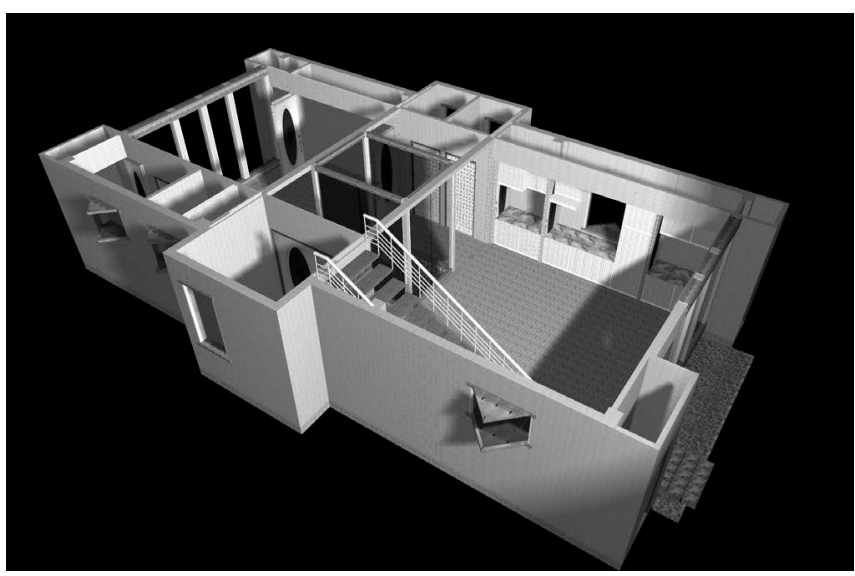

Illustration 7. Development of the second model: a detached two-story house. First floor. Even though each country has its own particular housing requirements, the search for architectural universals is being done. International building codes are an example of this globalization trend.

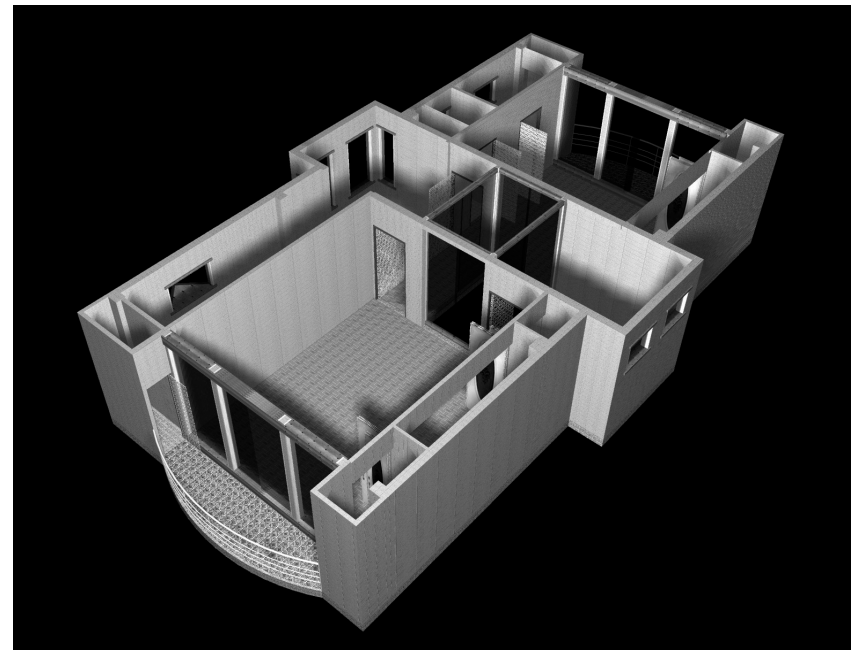

Illustration 8. Development of the second model: a detached two-story house. Second floor. Private areas are located upstairs.

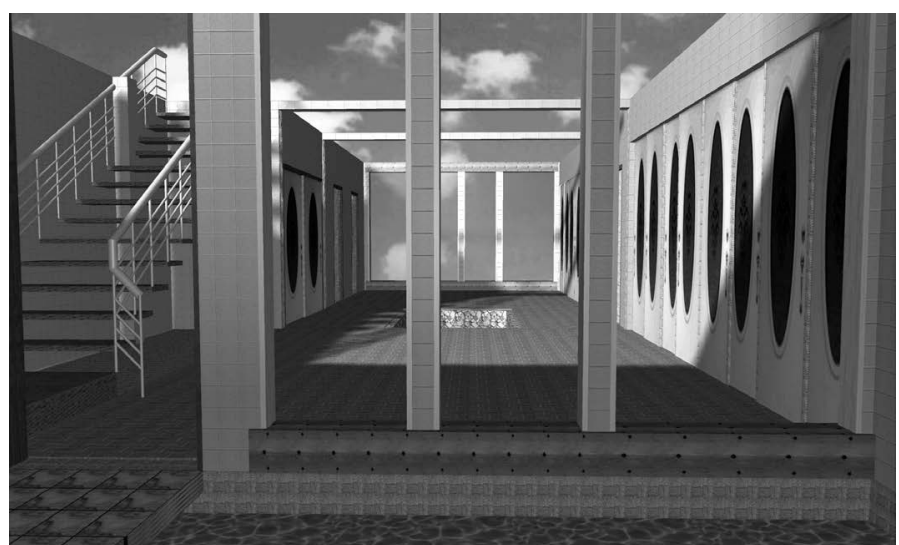

Illustration 9. This rendered image shows the "flexibility of space". This common characteristic to Japanese architecture is also applicable to western architecture with some adaptations. This building technique is an architectural universal regarding space-saving design. 


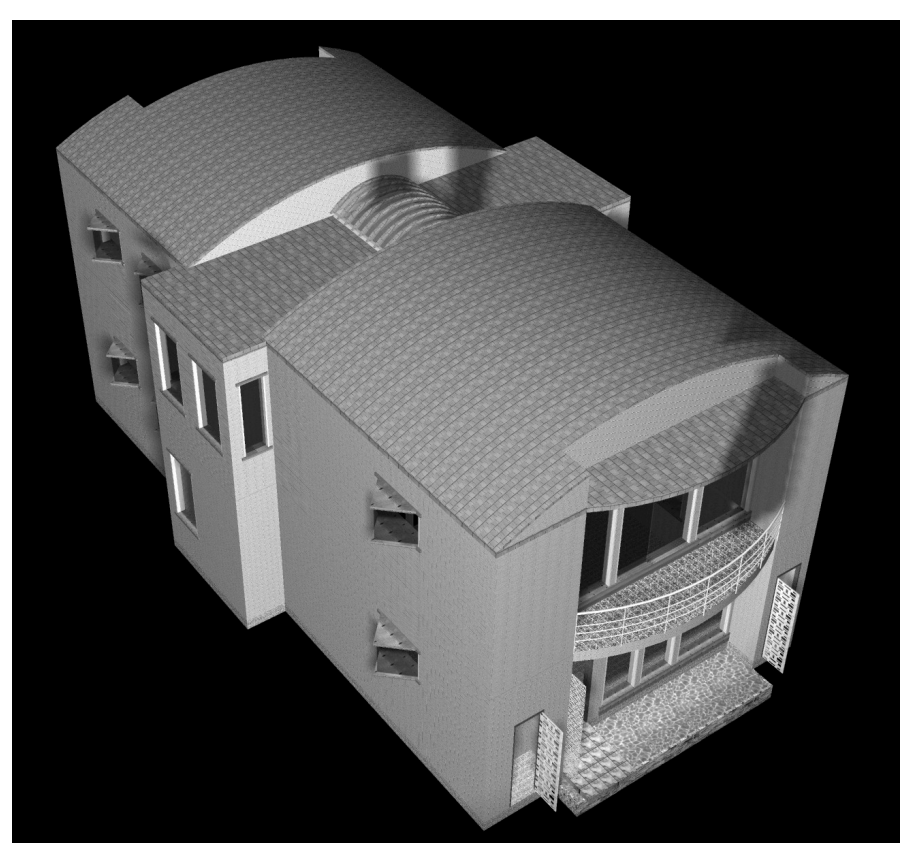

Illustration 10. The detached-house model has rigorously followed the recommendations regarding the storage space maximizing by increasing the closet usable space. Circulation areas have also been redesigned. Even though passageways that open onto the different rooms are necessary within the house, entrance halls and corridors should be minimized as much as possible. For detached houses, this is easier to be done due to the quadrangular conformation.

\section{Acknowledgements}

This article was supported by BRI (Building Research Institute) of Japan during my stay Tsukuba, the science city of Japan, and by UIDE (Universidad Internacional del Ecuador), Department of Research and Publications of Architecture.

\section{References}

[1] Brown, A. (1996) Small Spaces. Kodansha International Ltd., Tokyo.

[2] Inoue, M. (1985) Space in Architecture. Watanabe, H., Trans., Weatherhill, Tokyo.

[3] ICBO (1995) Handbook to the Uniform Building Code: An Illustrative Commentary. International Conference of Building Officials, ICBO, USA.

[4] Council of American Building Officials (1995) One and Two Family Dwelling Code. C.A.B.O, Washington DC.

[5] The Building Center of Japan (1990) The Building Standard Law of Japan. The Ministry of Construction: Building Guidance Division \& Urban Building Division: Housing Bureau, Japan.

[6] Statistics Bureau (1993) 1993 Housing Survey of Japan, Volume 1: Results for Japan. Management and Coordination Agency, Tokyo.

[7] The Building Center of Japan (1998) A Quick Look at Housing in Japan. 4th Edition, The Building Center of Japan, Japan.

[8] Building Research Institute (1996) Imported Housing User’s Manual. Ministry of Construction, Japan.

[9] Canadian Wood Council (1991) Wood Reference Handbook. CWC, Ottawa.

National Research Council of Canada (1996) NRC-CNRC Client Report: Canadian Systematized Housing: Concepts and Performance. IRC, Canada.

[10] CSIRO Australia (1996) Australian Single-Detached Houses. G.C. Foliente and L. Pham, Victoria.

[11] The Building Center of Japan (1990) Designation of Noncombustible Materials. The Ministry of Construction: Building Guidance Division \& Urban Building Division: Housing Bureau, Japan.

[12] The Building Center of Japan (1990) Designation of Quasi-Noncombustible Materials and Fire Retardant Materials. 
The Ministry of Construction: Building Guidance Division \& Urban Building Division: Housing Bureau, Japan.

[13] The Building Center of Japan (1990) Establishment of Technical Standards for Ensuring Structural Safety of Wood Frame Construction. The Ministry of Construction: Building Guidance Division \& Urban Building Division: Housing Bureau, Japan.

[14] The Building Center of Japan (1990) Establishment of Technical Standards for Ensuring Structural Safety of Log Construction. The Ministry of Construction: Building Guidance Division \& urban Building Division: Housing Bureau, Japan. 